\title{
Las reglas predeterminadas de decisión en el derecho. Bases para una reflexión teórica*
}

\section{Daniel Alejandro Monroy Cely}

RESUMEN. Las "reglas u opciones predeterminadas" son estructuras ubicuas en múltiples áreas del derecho. Aunque este tipo de reglas se han estudiado en el derecho de los contratos, más allá de este ámbito no han suscitado mayor interés en la doctrina jurídica de tradición civilista. Si bien esta doctrina ha sostenido reiteradamente que las reglas predeterminadas preservan per se un continuum en la libertad de decisión de sus destinatarios, este artículo refuta esta tesis y argumenta que estas reglas producen una profunda pero inadvertida afectación a la autonomía individual y la libertad de decisión individual. En esta perspectiva, el artículo reflexiona en torno a por qué en algunas áreas del derecho ciertos contenidos de las reglas predeterminadas pueden calificarse como éticamente inadmisibles. El artículo además sugiere algunos criterios preliminares para determinar "cómo" debiera diseñarse el contenido de las reglas predeterminadas.

PALABRAS ClAVE: reglas predeterminadas, elección activa, doctrina del derecho civil, autonomía individual, libertad de decisión.

Fecha de recepción: 25 de junio de 2019. Fecha de aceptación: 14 de agosto de 2020.

Para citar el artículo: Monroy Cely, D., "Las reglas predeterminadas de decisión en el derecho. Bases para una reflexión teórica", Revista de Derecho Privado, Universidad Externado de Colombia, n. ${ }^{\circ}$ 40, enero-junio 2021, 87-118, Dor: https://doi.org/10.18601/01234366.n40.04.

** Universidad Externado de Colombia, Bogotá, Colombia; docente investigador. Doctor en Derecho, Universidad Externado de Colombia, Bogotá, Colombia. Magíster en Derecho Económico, Universidad de Chile, Santiago de Chile, Chile. Especialista en Derecho Contractual, Universidad Externado de Colombia, Bogotá, Colombia. Contacto: daniel.monroy@uexternado.edu.co Orcid: 0000-0003-0519-7992. 


\section{Default Rules in the Law: Toward a Theoretical Framework}

Aвstract. Default rules are ubiquitous structures in multiple areas of law. Whereas these types of rules have been studied in contract law, beyond this area, default rules have not attracted much interest from civil law doctrine. Although this doctrine has repeatedly held that default rules preserve per se a continuum in the freedom of choice of their addressees, this paper contests this thesis and argues that these rules produce a deep but unnoticed impact on autonomy and individual freedom of choice. In this order, the paper reflects about why in certain areas of law and why certain contents of the default rules can be qualified as ethically inadmissible. The paper also suggests some preliminary criteria to determine "how" the content of the default rules should be designed.

KeYwords: default rules, active choice, civil law doctrine, individual autonomy, freedom of choice.

SumARIO. Introducción. I. (Algunas) características relevantes de las opciones predeterminadas de decisión. II. (Algunas) cuestiones problemáticas sobre las reglas predeterminadas en el derecho. Conclusiones. Referencias.

\section{Introducción}

El presente artículo constituye una reflexión respecto de un objeto de estudio que ha recibido escasa atención por parte de la doctrina jurídica, especialmente aquella de tradición civilista. El objetivo es delinear algunas cuestiones problemáticas de orden teórico que se desatan en un segmento del derecho, específicamente, una parte siempre presente en la estructura de diversos ámbitos de cualquier ordenamiento jurídico y que podríamos denominar las opciones o reglas predeterminadas de decisión.

La noción de estas reglas no es nueva en la literatura, pues ellas coinciden con las que algunos autores denominan "reglas por defecto" -o defaults- ${ }^{1}$. Empero, aunque estas reglas han recibido una creciente atención por parte de la doctrina jurídica de tradición anglosajona, especialmente en el ámbito del derecho de contratos ${ }^{2}$, han

1 Véase Choi, J., Laibson, D., Madrian, B. y Metrick, A., "Optimal defaults", The American Economic Review, vol. 93 n. 2, 2003, 180-185; Johnson, E. y Goldstein, D., "Do defaults save lives?", Science, vol. 302, n. ${ }^{\circ}$ 5649, 2003, 1338-1339.

2 Véase Ayres, I. y Gertner, R., "Filling gaps in incomplete contracts: an economic theory of default rules", The Yale Law Journal, vol. 99 n. ${ }^{\circ}$ 1, 1989, 87-130; BARnETt, R., "The sound of silence: default rules and contractual consent", Virginia Law Review, vol. 78, 1992, 821-911; SCHWARTz, A., "The default rule paradigm and the limits of contract law", Southern California Interdisciplinary Law Journal, vol. 3, 1994, 389-419. 
recibido menor atención fuera de este ámbito 3 y, por razones poco claras, han despertado un interés marginal en la literatura jurídica de tradición civilista, especialmente desde una perspectiva analítica.

Así las cosas, la hipótesis inicial de este artículo es que, si bien en la literatura jurídica (especialmente la de tradición civilista) suele aceptarse la noción y funciones que poseen las reglas predeterminadas en el ámbito del derecho contractual ${ }^{4}$, la misma literatura no ha prestado mayor interés a las implicaciones y efectos que producen este tipo de reglas en múltiples ámbitos relevantes -incluso fuera del derecho-, ni a las implicaciones que supone usar opciones predeterminadas en el derecho mismo. Sobre este particular, considérense anticipadamente los siguientes ejemplos.

Cuando un consumidor realiza una compra en una tienda, en ocasiones el vendedor solicita a aquel su correo electrónico: ¿significa esto que el consumidor está aceptando implícitamente que la tienda pueda enviarle publicidad a través del correo electrónico dado que no lo rechazó explícitamente? O, por el contrario, ¿significa que está rechazando el envío de publicidad dado que no lo aceptó explícitamente? Sobre el particular, algunos ordenamientos han establecido normas -reglas predeterminadas de decisión- en diferentes sentidos que señalan los efectos del silencio, de la inacción del consumidor sobre el envío de publicidad y, en general, respecto del alcance del tratamiento que la empresa puede darle a la información personal que obtiene del consumidor al realizar una transacción ${ }^{5}$.

Algo similar ocurre con el paradigmático caso de las reglas predeterminadas que otorgan efectos jurídicos a la inacción de las personas en lo que concierne a la voluntad de donar o no sus órganos al fallecer. Como se sabe, en algunos países existen normas jurídicas que (pre)determinan que, en caso de que la persona no actúe, es decir, en ausencia de una "elección activa" en sentido contrario, se presume que la persona consintió en la donación de sus órganos post mortem. Este es el sistema de elección tipo opt-out, y caracteriza el hecho de que la ausencia de elección activa se interpreta como voluntad afirmativa de ser donante. Simultáneamente, otros or-

3 Vale destacar la compilación de artículos contenida en un volumen especial del Florida State University Law Review, denominado Default Rules in Private and Public Law, de 2006, en el que se incluyen varios textos con diversos tratamientos teóricos de las "defaults" en el contexto del derecho de contratos y otros ámbitos como el derecho constitucional, el derecho del medio ambiente o el derecho de familia.

4 Sobre las reglas predeterminadas en el derecho de contratos local, véase MonRoy, D., "Reglas supletivas 'sancionatorias' en el derecho de contratos colombiano: el caso del contrato de transporte", Revista de Derecho Privado, Universidad Externado de Colombia, n. ${ }^{\circ} 30,2016,221-254$ y Monroy, D., "Acerca del diseño óptimo de las reglas predeterminadas en el derecho de contratos", en AA.vV., Colección Enrique Low Murtra: Derecho Económico, Bogotá, Universidad Externado de Colombia, 2017, 15-62.

5 Por ejemplo, la Directiva europea 2002/58/CE establece como regla general que, a menos que el consumidor lo acepte explícitamente, las empresas no podrán enviarle publicidad a través de correo electrónico. En contraste, en Estados Unidos, la CAN-SPAM Act de 2003 establece que las empresas pueden enviar publicidad a cualquier persona (consumidor o no) incluso sin su consentimiento explícito, a menos que el destinatario solicite explícitamente a la empresa que cese dicho envío. 
denamientos establecen la regla contraria, según la cual la inacción de la persona se presume como voluntad negativa de donar sus órganos. Este se denomina sistema de elección tipo opt-in ${ }^{6}$.

Un caso análogo a nivel local y relativo al tratamiento de datos personales ( $h a$ beas data) es el de la autorización con que en su momento el legislador exigió que contaran las empresas -responsables del tratamiento de datos personales- para que pudiesen almacenar, utilizar y tratar información personal obtenida de sus clientes. En concreto, dado que, previo a la expedición de la Ley de Protección de Datos Personales (Ley 1581 de 2012), existían empresas que poseían información personal de sus clientes -titulares de la información-, entonces dicha ley estableció que las mismas empresas debían obtener autorización de los titulares para continuar almacenando y utilizando la información personal. En desarrollo de dicha ley, el Decreto Reglamentario 1377 de 2013 señaló que las empresas podían utilizar diversos mecanismos de comunicación, por ejemplo, enviar mensajes a través de correo electrónico a los titulares de la información para obtener dicha autorización. Lo destacable para nuestros efectos es que el artículo 10.4 del decreto incluyó una regla predeterminada de decisión, según la cual, si en el término de treinta días contados a partir de la comunicación de la empresa, el titular no manifestaba explícitamente su intención de que los datos personales fuesen suprimidos, tal inacción se entendía como consentimiento del titular para que la empresa continuara realizando el tratamiento de los datos contenidos en sus bases de datos. Como se corrobora, lo que estableció la regulación local fue una regla predeterminada tipo opt-out, pues la ausencia de una "elección activa" del titular de la información se interpreta como voluntad afirmativa de que sus datos puedan seguir siendo almacenados y utilizados por la empresa.

Es importante destacar que en este caso la regulación sobre privacidad y tratamiento de información personal constituye el desarrollo legislativo de un derecho fundamental (art. 15 de la Constitución), lo que comúnmente suele justificar que las normas jurídicas aplicables se consideren de orden público. Sin embargo, este mismo ejemplo corrobora que existe un amplísimo campo de acción de las reglas predeterminadas de decisión (más allá del derecho de contratos), y al mismo tiempo es una señal sobre la pertinencia de una discusión teórica más profunda sobre el rol de las reglas predeterminadas incluso en ámbitos como el derecho constitucional ${ }^{7}$.

Teniendo en mente este mismo caso sobre el tratamiento de información personal en Colombia, de él se infiere que el hecho de que incluso las normas aplicables a cierta institución jurídica se consideren de orden público no excluye que en este

6 Para un resumen y clasificación de los diferentes sistemas de presunción de donación de órganos post mortem en diferentes países de Europa, véase Gevers, S., JANSSEN, A. y Friele, R., "Consent systems for post mortem organ donation in Europe", European Journal of Health Law, vol. 11, 2004, 175-186.

7 Para una discusión acerca de las reglas predeterminadas en el contexto del derecho constitucional, véase FEREJOHn, J. y FriedMAn, B., "Toward a political theory of constitutional default rules", Florida State University Law Review, vol. 33, n. ${ }^{\circ}$ 3, 2006, 825-860. 
ámbito las reglas predeterminadas jueguen un rol preponderante. Esto mismo ocurre, por ejemplo, con el régimen jurídico aplicable a la sucesión mortis causa. Así, aunque doctrinalmente se suele decir que en este ámbito las normas se consideran mayoritariamente de orden público, nótese que este régimen está más bien conformado en buena parte por reglas predeterminadas, esto en el sentido de que lo que indica el legislador es que, en general, a menos que en vida el difunto hubiese expresado explícita y activamente su propia voluntad a través de un testamento, su inacción se interpreta entonces como voluntad individual de que las normas predeterminadas sobre sucesión tengan pleno efecto al momento de fallecer.

Ahora bien, aunque no pareciera prima facie relevante, vale insistir en la idea de que en contextos inicialmente indiferentes al derecho existen también innumerables casos en los que son particularmente relevantes las opciones predeterminadas de decisión. A manera de ejemplo, considérese la situación en la que alguien adquiere un nuevo smartphone. En este caso, existen una gran cantidad de opciones predeterminadas por el fabricante del producto ( $v . g r$., el fondo de pantalla, el tono de timbre, las aplicaciones preinstaladas, etc.) que el usuario puede modificar libremente en cualquier momento y según sus propias preferencias, pero, si no opta por hacerlo, se asume que su inacción se equipara a la decisión de dejar la configuración de fábrica como la elección definitiva del usuario. Lo propio ocurre en el contexto del software. De hecho, en este ámbito las opciones predeterminadas de decisión son también la regla general. Así, al instalar un procesador de palabras (v.gr., Microsoft Word) en un computador, si el usuario no especifica nada diferente, es decir, si decide no actuar, se asume que su voluntad fue mantener la configuración original de fábrica como la configuración final, por lo que la inacción del usuario supone entonces que aceptó como propias las decisiones predeterminadas por el fabricante, como el tipo y tamaño de letra, las márgenes y un sinnúmero de preconfiguraciones adicionales ${ }^{8}$.

Con estos ejemplos de trasfondo podemos afirmar, por un lado, que las opciones predeterminadas de decisión están presentes y se proyectan en diversas áreas propias de cualquier ordenamiento jurídico: el derecho del consumo, el derecho de familia, el derecho constitucional, el derecho de contratos, etc. Al mismo tiempo, estas reglas también están presentes y cumplen importantes funciones análogas en otros campos inicialmente ajenos al derecho. Por tanto, un presupuesto de este artículo es que las opciones predeterminadas de decisión constituyen estructuras ubicuas que se replican (son omnipresentes) en múltiples ámbitos dentro y fuera del derecho ${ }^{9}$.

8 Para un análisis de las implicaciones cognitivas y jurídicas de las opciones por defecto en el contexto del software, véase KESAN, J. P. y SHAH, R., "Setting software defaults: perspectives from law, computer science and behavioral economics", Notre Dame Law Review, vol. 82, n. . 2, 2006, 583-634.

9 La omnipresencia y ubicuidad de las reglas predeterminadas en los diversos ámbitos del derecho y fuera de él es explícitamente reconocida por autores como WILLIS, L., "When nudges fail: slippery defaults", The University of Chicago Law Review, vol. 80, n. ${ }^{\circ} 3,2013,1155-1229$, y THALER, R., Sunstein, C. y Balz, J., "Choice architecture", en Shafir, E., The Behavioral Foundations of Public Policy, New Jersey, Princeton University Press, 2013, 428-439. 
Por otro lado, los ejemplos preliminares en comento permiten evidenciar una noción in genere -incluso más allá del derecho- de lo que se considera una opción o regla predeterminada de decisión. Al respecto, de manera consistente con la literatura, este artículo sostiene que el tipo de reglas en mención constituyen estructuras que a priori describen el contenido sustancial de la decisión que se asume toma una persona si es que opta por no actuar, es decir, si es que no efectúa una elección activa. Por tanto, una opción predeterminada de decisión es aquella regla que ex ante con respecto a la decisión individual define un punto de referencia inicial que se entiende como la elección definitiva si es que el individuo opta por no decidir activamente ${ }^{10}$.

Teniendo como referencia el presupuesto y la definición en comento, y haciendo uso de un método deductivo y analítico, este artículo pretende profundizar en algunas características relevantes de las reglas predeterminadas de decisión, características estas que, como se verá, comportan ciertas cuestiones problemáticas de orden teórico que han pasado inadvertidas especialmente por la literatura jurídica civilista. Para tales efectos, el artículo se organiza en tres secciones: en la primera sección se destacan tres de las características relevantes y definitorias de las reglas predeterminadas (I); en la segunda sección -y a partir de las características descritas- se delinean algunas cuestiones problemáticas de orden positivo (II.A) y otras de orden normativo (II.B) que suscitan estas reglas como objeto de estudio en el derecho. En la tercera parte se presentan unas breves conclusiones.

\section{I. (Algunas) características relevantes de las opciones predeterminadas de decisión}

Tres características relevantes se destacan de la definición de una opción predeterminada de decisión. En su orden: que esta estructura de toma de decisión se opone a lo que se ha denominado la estructura de decisión de "elección activa" (A); que en presencia de una regla predeterminada se asume que esta preserva la autonomía y libertad de decisión individual, esto es, la libertad de modificar, mediante una "elección activa", la decisión predefinida (B). Finalmente, que estas reglas son, sin embargo, el resultado de una decisión previa y deliberada de un diseñador que puede ser incluso el propio legislador o regulador (C).

10 Sobre esta propuesta de definición de opción predeterminada Johnson et al. afirman que una opción predeterminada describe la decisión del individuo cuando este no toma ninguna elección activa; véase Johnson E., Bellman, S. y Lohse, G. "Defaults, framing and privacy: why opting in-opting out", Marketing Letters, vol. 13, n. ${ }^{\circ}$ 1, 2002, 7. En el mismo sentido, véase Johnson, E. y GoldSTEIN, D., "Decisions by default", En Shafir, E., The Behavioral Foundations of Public Policy, New Jersey, Princeton University Press, 2013, 417. 


\section{A. Opción predeterminada vs. elección activa}

Si las opciones predeterminadas se dirigen a determinar el contenido sustancial de la decisión ante la eventual "inacción” del individuo, entonces, por definición, esta forma de estructurar la decisión es lo contrario de aquella otra en la que el contenido sustancial se determina a través de una "elección activa" 11 . Por tanto, una estructura de "elección activa" supone la inexistencia de una opción predeterminada, luego, solo actuando (elegir eligiendo) es posible proveer algún contenido sustancial o efecto a la decisión individual.

Para comprender mejor el alcance del contraste entre una opción predeterminada y una "elección activa", considérese el caso de una persona que ingresa a una tienda cualquiera, contempla los productos exhibidos y posteriormente sale. Un observador de esta conducta (v.gr., el vendedor de la tienda) no podría asumir que esta conducta pasiva se interpreta como una decisión o siquiera una intención vinculante de comprar algo. Por tanto, en este caso no existe ninguna opción predeterminada de decisión que otorgue algún contenido o efecto a la inacción de la persona. En este caso, se requiere algún tipo de "elección activa" para determinar cuando menos la intención -de comprar- de la persona. Similar situación se replica en el citado ejemplo de la instalación del software. En este caso, los propios ingenieros diseñan el software de forma tal que durante el proceso de instalación, el usuario deba tomar ciertas "elecciones activas", entre otras, que acepte -a veces mediante un clic- los términos de la licencia del software si es que es su intención utilizarlo.

En este sentido, en presencia de una opción predeterminada, la "elección activa" es una acción contingente a fin de determinar el contenido sustancial de la decisión individual, y por tanto sus efectos. En contraste, existen múltiples casos -incluso en el contexto del derecho- en los cuales dicha elección activa no es algo contingente, sino que se requiere de ella a fin de determinar exógena e inequívocamente el contenido sustancial de la decisión, para luego adjudicarle algún efecto.

Ahora, este contraste entre "opción predeterminada" y "elección activa" pone en evidencia algunas cuestiones problemáticas que es preciso mencionar. Así, nótese que, en sentido estricto, incluso en los ejemplos recién mencionados, optar por la inacción sí provee un contenido a la decisión individual, luego no es cierto que se requiera necesariamente una "elección activa" para determinar dicho contenido. Esto no es una cuestión trivial. En efecto, podría afirmarse que cuando aquella persona ingresa a la tienda, contempla los productos y posteriormente sale, esta conducta es interpretable precisamente como intención de "no comprar", lo cual sí describe el contenido de una decisión stricto sensu que es exógena e inequívocamente determi-

11 Véase Sunstein, C. y Thaler, R., "Libertarian paternalism is not an oxymoron", The University of Chicago Law Review, vol. 70, n. ${ }^{\circ} 4,2003,1173$, donde se denomina a esta estructura de la toma de decisión individual como "de elección activa requerida" y se la contrasta con la estructura de toma de decisión derivada de las opciones predeterminadas, en la cual, según los autores, el individuo "elige no eligiendo". 
nable a partir de la propia conducta omisiva del individuo, y que incluso produce efectos identificables. Adviértase que, ya sea que esa persona rechace una oferta explícita del vendedor de la tienda -mediante una "elección activa"- o que simplemente entre y salga de ella, en los dos casos el efecto de la conducta es el mismo. Lo propio ocurre en el ejemplo de la instalación del software: en este caso, si el usuario omite dar clic en la opción de aceptación de los términos de la licencia, esta inacción se interpreta precisamente como voluntad explícita de rechazar tales términos, a lo cual se le anuda la consecuencia de no poder o querer utilizar el software.

Respecto de esta observación, se considera necesario hacer una precisión para caracterizar dos variedades de la estructura de toma de decisión de "elección activa", a saber: la elección activa opcional y la elección activa forzosa ${ }^{12}$. En concreto, en el ejemplo de la tienda, no existe, stricto sensu, ningún efecto adverso que se derive de la conducta de la persona. En este caso, cualquier conducta, sea entrar, salir de la tienda, optar por comprar o por rechazar una oferta explícita, es siempre y en todos los casos una decisión opcional, y si la persona no toma ninguna elección "activa" no existe aquí ninguna consecuencia adversa respecto de ella misma. En contraste, en el ejemplo de la instalación del software, nótese que la inacción no es una posibilidad realmente disponible, luego conceptualmente es una estructura de decisión que va en una dirección contraria a la estructura de opciones predeterminadas de decisión. En este segundo caso, es forzosamente necesaria -no es opcional- la elección activa por parte del individuo. Se trata entonces de casos distintos, sobre los que volveremos en la segunda parte del artículo.

\section{B. La regla predeterminada preserva un continuum en la libertad de elección individual, decidir o no decidir}

Además de la "elección activa", otra estructura que se diferencia de la decisión basada en una regla predeterminada es la conocida "regla imperativa". En contraste con aquella, esta última se caracteriza por el hecho de restringir la libertad individual en la toma decisión, es decir, elimina la posibilidad de que la persona pueda elegir activamente alguna opción de decisión en específico. Cabe decir que, en el derecho de contratos, la distinción entre reglas predeterminadas y reglas imperativas es bastante clara e ilustrativa. Sobre el particular, Zamir y Medina ${ }^{13}$ señalan que las primeras son aquellas reglas que resultan vinculantes para las partes del contrato a menos que decidan aparatarse de ellas o acuerden explícitamente algo en torno a las mismas; a su turno, las segundas son aquellas reglas que resultan vinculantes para las partes incluso a pesar de que intenten apartarse o acordar explícitamente algo respecto de

12 Sunstein, C., "Impersonal default rules vs. active choices vs. personalized default rules: a triptych", Working Paper, 2013, 28.

13 Zamir, E. y Medina, B., Law, Economics, and Morality, New York, Oxford University Press, $2010,317$. 
ellas $^{14}$. Más allá del derecho contractual, vale destacar también las normas que diferentes ordenamientos han adoptado en materia de ahorro pensional. Así, de conformidad con la regulación colombiana, se prohíbe que los trabajadores puedan optar por no ahorrar, es decir, en este caso se trata de una regla que "imperativamente" ordena que los trabajadores ahorren parte del salario en un fondo de pensiones. En contraste, en Estados Unidos la misma decisión de ahorro suele no estar sujeta a este mismo tipo de restricciones, sino que depende más bien de la decisión voluntaria de cada trabajador.

Empero, es en el contexto de los ordenamientos que más promocionan programas voluntarios de ahorro pensional en donde precisamente las opciones predeterminadas han demostrado una destacada utilidad. En efecto, en Estados Unidos los denominados planes de retiro voluntario 401(k) son programas en los que el trabajador autoriza voluntariamente a su empleador para que retenga una parte del salario y la dirija a una cuenta de inversión a la que solo puede accederse una vez cumplida la edad de jubilación. Al respecto, existe una abultada literatura que analiza en términos agregados la conducta de los trabajadores y el efecto que produce el hecho de que la opción predeterminada al momento de ser contratados es que los mismos queden inscritos en un programa de ahorro (sistema opt-out $)^{15}$. Vale agregar que este programa de ahorro voluntario suele incluir otras opciones predeterminadas, tales como el porcentaje de salario a retener y el grado de riesgo de la inversión. Empero, el mismo programa permite que el trabajador modifique libremente y según sus propias preferencias tales opciones predeterminadas, e incluye además la posibilidad de que -mediante una elección activa- el trabajador se retire del plan de ahorro.

Lo que se pretende destacar es que la libre voluntad y autonomía de los trabajadores se predica que está garantizada en tanto se les permite ingresar, modificar, permanecer o retirarse cuando así lo prefieran. Ahora bien, nótese que esta misma circunstancia se replica en todos y cada uno de los ejemplos hasta ahora expuestos sobre opciones predeterminadas. Así, en el mencionado caso de la regulación colombiana sobre utilización y tratamiento de datos personales, aunque la opción predeterminada es que la inacción del titular de los datos se interpreta como voluntad afirmativa de que estos sean utilizados por la empresa, la misma regulación (art. 9 del Decreto 1377 de 2013) establece que el titular puede solicitar en cualquier mo-

14 Esta distinción entre reglas predeterminadas y reglas imperativas en el derecho de contratos se sostiene incluso en la doctrina jurídica civilista: véase ArruÑadA, B., "The role of institutions in the contractual process", en DefFains, B. y Kirat, T., Law and Economics in Civil Law Countries, Amsterdam, Elsevier Science, 2001, 154.

15 Véase Choi, J., Laibson, D., Madrian, B. y Metrick, A., "Defined contribution pensions: plan rules, participant choices, and the path of least resistance", Tax Policy and the Economy, vol. 16, 2002, 67-113; Madrian, B. y ShEA, D., "The power of suggestion: inertia in 401(k) participation and savings behavior", The Quarterly Journal of Economics, vol. 116, n. ${ }^{\circ} 4,2001,1149-1187$; BESHEARs, J., Choi, J., LAIBSOn, D. y MADRIAn, B., "The importance of default options for retirement saving outcomes: evidence from the United States", en Brown, J., Liebman, J. y Wise, D., Social Security Policy in a Changing Environment, Chicago, University of Chicago Press, 2009, 167-195. 
mento -mediante una elección activa- la supresión de los datos personales o revocar la autorización de tratamiento por parte de la empresa.

Con todo, la segunda característica definitoria que se destaca de las opciones predeterminadas es que estas no afectan ni obstaculizan, por el contrario, constituyen una garantía de la libertad de decisión individual ${ }^{16}$. En ese sentido, estas reglas protegen y ubican sobre un mismo plano cualquier conducta que despliegue el individuo, desde elegir activamente algo diferente a lo predeterminado por la regla hasta optar por no actuar después de que la opción predeterminada se haya convertido en la decisión definitiva, si es lo que la persona prefiere. Por tanto, se dice que la regla predeterminada garantiza un continuum de la libertad de elección individual que va desde proteger la libertad del individuo si este "decide no decidir" y va hasta la protección de la libertad de elegir activamente, si es que el individuo "decide decidir"17.

Lo anterior permite resaltar otro punto particularmente relevante respecto de la aproximación analítica a las reglas predeterminadas como objeto de estudio: si se dice que estas reglas preservan dicho continuum en la libertad de elección, al mismo tiempo, podría sostenerse que esta garantía constituye una salvaguarda que protege al individuo si es que la opción predeterminada resulta perjudicial para él, o si es que dicha opción no se adecua a sus preferencias individuales. Si esto es así, entonces podría afirmarse que el contenido sustancial de la opción predeterminada (incluso si se trata de una norma jurídica) no sería prima facie una cuestión particularmente relevante, pues, independientemente de cómo está diseñada originalmente la regla (es decir, si se trata de un sistema tipo opt-in o de uno tipo opt-out), la misma regla contiene dicha salvaguarda que garantiza que el individuo corrija libremente este diseño si es que lo considera inadecuado o perjudicial para sí mismo ${ }^{18}$.

Lo recién dicho quizá sea una de las razones por las cuales -como se ha recordado- las opciones predeterminadas han despertado un interés marginal -desde una perspectiva teórica y como objeto de estudio en sí mismo- en la literatura jurídica (civilista). En efecto, teniendo en mente la mencionada garantía de la libertad en la decisión individual que supone cualquier regla predeterminada, podría decirse que una regla tipo opt-out respecto de la donación de órganos post mortem no podría considerarse prima facie ni peor ni mejor que una regla opt-in. En este caso, si una persona considera contrario a sus intereses o preferencias que sus órganos sean

16 Johnson, E., Shu, S., Dellaert, B., Fox, C., Goldstein, D., Häubl, G. y Weber, E., "Beyond nudges: tools of a choice architecture", Marketing Letters, vol. 23, n. ${ }^{\circ} 2,2012,491$.

17 "Por definición, las opciones predeterminadas permiten a las personas escoger cualquier alternativa, pueden, simultáneamente, preservar la libertad de elección e influir en la conducta individual”. DiNNER, I., Johnson, E., Goldstein, D. y Liu, K., "Partitioning default effects: why people choose not to choose", Journal of Experimental Psychology, vol. 17, n. ${ }^{\circ}$ 4, 2011, 332.

18 De esta manera es destacado por Carroll et al. al afirmar que "las opciones predeterminadas no deberían importar si los agentes creen que estas han sido establecidas arbitrariamente y si es fácil para ellos elegir [activamente] algo distinto". Carroll, G., Choi, J., Laibson, D., Madrian, B. y Metrick, A., "Optimal defaults and active decisions", The Quarterly Journal of Economics, vol. 124, n. ${ }^{\circ}$, 2009, 1639-1674. 
extraídos al morir, cualquiera de los dos sistemas permite y no obstaculiza que esta decisión sea la elección final. Así, bajo un sistema opt-out, esta persona podrá elegir activamente en cualquier momento de su vida que su decisión es no ser donante. Simultáneamente, bajo un sistema opt-in, la inacción de la misma persona será suficiente para interpretar la misma decisión. Por tanto, si, a nivel local, el Decreto 1377 de 2013 hubiese establecido, hipotéticamente, que la inacción (la ausencia de manifestación explícita) del individuo debía interpretarse como rechazo a que sus datos personales pudieran ser tratados y utilizados por las empresas, el mismo individuo hubiera podido corregir mediante una elección activa esta decisión si es que no se adecuaba a sus propias preferencias. En este último caso, no parece que exista entonces un argumento que permita sostener que esta hipotética regla fuese más o menos garantista del derecho fundamental del habeas data si se compara con la regla que efectivamente se estableció en la regulación colombiana.

\section{La opción predeterminada es siempre consecuencia de una "arquitectura" de la decisión}

Respecto de la tercera característica definitoria de una opción predeterminada, nótese que en todos los ejemplos mencionados el contenido de la que se considera la opción predeterminada ha sido consciente y deliberadamente definido por alguien ex ante con respecto a la toma de decisión individual. Así, es algún ingeniero de software quien, al diseñar el procesador de palabras, define, por defecto, el tipo y tamaño de letra y las márgenes de los documentos. En el mismo sentido, la reciente ratificación a nivel local de la regla sobre presunción de donación de órganos (Ley 1805 de 2016) fue el resultado de un proceso y de una decisión deliberada del legislador, según la cual se asume que la inacción individual equivale a la voluntad de querer ser donante al momento de la muerte, pero, no obstante, según la propia ley (art. 4), esta presunción puede ser modificada mediante una "elección activa" en contrario (regla tipo opt-out).

Así las cosas, la tercera característica que se destaca de las opciones predeterminadas es que estas no surgen espontánea ni azarosamente en la realidad, como tampoco son un producto de la naturaleza. Por el contrario, son el resultado de una decisión previa y deliberada de un diseñador, es decir, un "arquitecto de la decisión"19, que puede ser tanto un ingeniero de software como, incluso, el propio regulador. Por tanto, cuando estos "diseñadores" definen cuál es la opción predeterminada, están proveyendo una estructura de decisión, diseñada deliberadamente para poder determinar exógena e inequívocamente el contenido sustancial, la estructura interna de la decisión individual. Esto es lo que algunos denominan in genere como una expresión 
de la "arquitectura de la decisión", respecto de la cual el diseño y establecimiento de opciones predeterminadas es quizá el ejemplo más destacable ${ }^{20}$.

\section{II. (Algunas) cuestiones problemáticas sobre las reglas predeterminadas en el derecho}

Ahora bien, más allá de la noción propuesta y de las características destacadas, lo cierto es que, como objeto de estudio, las reglas predeterminadas suscitan una serie de cuestiones problemáticas tanto de orden positivo como normativo, a las cuales la doctrina jurídica - particularmente la de tradición civilista- ha prestado apenas marginal atención. En este orden de ideas, la presente sección se dirige precisamente a analizar -si bien de manera no exhaustiva- algunas de estas cuestiones.

Al respecto, algunas de las problemáticas asociadas a las opciones o reglas predeterminadas de decisión como objeto de estudio, se derivan de los "verdaderos" efectos, la incidencia que se ha demostrado estas opciones generan en la decisión individual. Sobre el particular, y pese a que se haya dicho previamente (I.B) que las reglas predeterminadas se caracterizan por preservar un continuиm en la libertad de elección individual, y que esta garantía se erige como una salvaguarda dirigida a proteger al propio individuo de resultados eventualmente perjudiciales o que no se adecuen a sus preferencias individuales, lo cierto es que tales opciones ejercen una relevante pero a veces inadvertida incidencia en la toma de decisión individual, que incluso tiene importantes efectos agregados. Aunque dispersa, dicha incidencia se encuentra bastante bien documentada en la literatura.

A manera de ilustración sobre este punto, se ha dicho, por ejemplo, que la principal razón por la cual la empresa de AOL Inc. adquirió a la empresa Netscape a finales de los años noventa no fue el interés en el software que esta última producía sino el hecho de que aquella quería acceder directamente al $40 \%$ de los usuarios de su navegador, que se sabía, no habían modificado la página web inicial que la misma Netscape había establecido como opción predeterminada ${ }^{21}$. En esta misma línea argumentativa, es bien conocido que mientras que países como Austria, Francia o Hungría han alcanzado una tasa de $99.9 \%$ de presuntos donantes de órganos post mortem mediante el establecimiento de una regla predeterminada de presunción de donación de órganos (opt-out), países vecinos como Alemania o Dinamarca han alcanzado una tasa de tan solo el $12 \%$ y el $4 \%$ respectivamente, pero utilizando la regla contraria $(\text { opt-in })^{22}$.

20 Como lo ha destacado Sunstein, "aquellos que determinan las reglas predeterminadas actúan como arquitectos de la decisión, en el sentido de que establecen el marco social en el cual ocurren las decisiones. No es posible prescindir del marco social y, por tanto, es inevitable la definición de alguna arquitectura de la decisión". Sunstein, C., "Impersonal default rules vs. active choices vs. personalized default rules: a triptych", cit., 3 .

21 KeSAn, J. P. y SHAH, R., "Setting software defaults", cit., 587.

22 Johnson, E. y Goldstein, D., "Decisions by default", cit., 418. 
Vale señalar en este punto que, si bien en la sección introductoria señalamos que, aunque ilustrativo, el caso de las opciones predeterminadas en el contexto del software parecía prima facie ser algo indiferente para el derecho, en realidad esta es una afirmación que -como ya logra inferirse- es menester relativizar.

Al respecto, son bien conocidas las medidas adoptadas por la Comisión Europea en 2009 en contra de Microsoft por incluir el navegador Internet Explorer como "opción predeterminada" dentro del paquete de instalación del sistema operativo Windows. En este caso, la Comisión sostuvo que, dada la posición dominante de Microsoft en el mercado de sistemas operativos, establecer el Explorer como "opción predeterminada" se consideraba una conducta que atentaba contra la libre competencia pues imponía barreras a los competidores, desincentivaba la innovación en el mercado de navegadores y afectaba negativamente la libertad de elección de los usuarios, ello pese a que -según la defensa de Microsoft- era posible que el mismo usuario libremente desinstalara la "opción predeterminada" en cualquier momento e instalara cualquier otro navegador, si era lo que él quería ${ }^{23}$.

De acuerdo con la terminología del presente artículo, puede decirse que en este caso el argumento de Microsoft era que no estaba infringiendo la regulación dado que no era una imposición, no siendo "imperativo" que el usuario utilizara el Explorer. La empresa alegó que, muy por el contrario, el sistema Windows garantizaba dicho continuum en la libertad de elección del usuario (i.B), ya fuese que decidiese no actuar, y por tanto optara (implícitamente) por utilizar el navegador predeterminado (Explorer), o que tomase una "elección activa" a fin de modificar dicha opción. Este argumento fue rechazado por la Comisión, y en consecuencia ordenó a Microsoft que en lugar de ofrecer el Explorer como "opción predeterminada" debía modificar el proceso de instalación de Windows a fin de que en el curso del mismo apareciese una ventana en la que el usuario pudiese escoger, mediante una "elección activa", entre doce navegadores (Chrome, Firefox, incluso el mismo Explorer, etc.); además, se le advirtió a la empresa que dichos navegadores debían aparecer de manera aleatoria en una misma ventana, sin que siquiera Microsoft pudiera "recomendar" alguno.

Este ejemplo, particularmente la argumentación de la Comisión Europea, permite destacar dos problemáticas teóricas asociadas a las reglas predeterminadas como objeto de estudio que se desarrollan a continuación. La primea (de orden positivo) es que resulta objetable la tesis -arriba expuesta- de que las opciones predeterminadas de decisión efectivamente protegen o garantizan dicho continuum de la libertad de elección individual, y por tanto, no se sostiene la tesis de que estas reglas supongan una salvaguarda que proteja al propio individuo si es que la opción predeterminada resulta perjudicial para este o si no se adecua a sus preferencias individuales (I.B). Si esto es así, se infiere una segunda problemática (de orden normativo), en concreto, que la forma cómo está diseñada originalmente una opción predeterminada, e inclu- 
so la existencia misma de esta, no debiera permanecer como una cuestión de interés apenas marginal por parte del derecho.

\section{A. Acerca de la "pegajosidad" de la opción predeterminada de decisión}

En su orden, respecto de la primera problemática señalada (de orden positivo), algunos autores sostienen que cuestiones tales como la actitud de los usuarios respecto de las opciones predeterminadas en el ámbito del software (v.gr., el navegador de internet o el servicio de búsquedas que utilizan), la conducta de los consumidores respecto de la manera como las empresas tratan su información personal, las decisiones sobre la cantidad de dinero que ahorran, e incluso los comportamientos de las partes contratantes al momento de negociar un acuerdo, no pueden comprenderse tanto como la consecuencia de la decisión "auténticamente" autónoma, libre y deliberada de cada persona, sino, más bien, como una función de la manera en que está diseñada originalmente la opción predeterminada en cada $\mathrm{caso}^{24}$. En términos más generales, lo que se pretende resaltar es que, con independencia del contexto (sea este relevante o no para el derecho), siempre que en dicha "arquitectura" se encuentre el individuo ante una opción predeterminada de decisión se generará una propensión sistemática y contraria a tomar una "elección activa" y, más bien, se tenderá a aceptar pasivamente dicha opción predeterminada, sin importar su contenido sustancial ${ }^{25}$. La mayoría de los autores suelen referirse a este efecto como "pegajosidad" (stickiness) de la opción predeterminada ${ }^{26}$.

24 Para una discusión jurídica respecto de la incidencia de las opciones predeterminadas en las decisiones individuales en el contexto del software, véase STUске, M., "Behavioral antitrust and monopolization", Journal of Competition Law \& Economics, vol. 8, n. ${ }^{\circ}$ 3, 2012, 545-574, y STUске, M., "Behavioral exploitation and its implications on competition and consumer protection policies", en AA.vv., The Pros and Cons of Consumer Protection, Växjö, Davidsons Tryckeri, 2012, 77-122. Sobre el mismo punto pero respecto del tratamiento de información personal en internet, véase KESAN J. y SнAн R., "Setting software defaults", cit. y WILLIS, L. "Why not privacy by default?", LoyolaLA Legal Studies, Paper No. 2013-37, 2014, 1-74. En lo relativo al mismo efecto sobre la tasa de donantes véase Johnson E. y Goldstein D., "Do defaults save lives?”, cit.; Johnson, E. y Goldstein, D., "Decisions by default", cit. Respecto a las decisiones de ahorro y pensiones véase MADRIAN, B. y SHEA, D., "The power of suggestion: inertia in 401(k) participation and savings behavior", cit.; Сног, J. et al., "For better or for worse: default effects and 401(k) savings behavior", en WISE D., Perspectives on the Economics of Aging, Chicago, University of Chicago Press, 2004, 81-125. En cuanto a los efectos de las reglas predeterminadas en los diseños y los acuerdos contractuales véase Korobrin, R., The Status Quo Bias and Contract Default Rules, cit.; Korobkin, R. "Inertia and preference in contract negotiation: the psychological power of default rules and form terms", Vanderbilt Law Review, vol. 51, n. ${ }^{\circ}$ 6, 1998, 1583-1651, entre otros.

25 "En muchos casos, los agentes económicos no hacen elecciones activas. En su lugar, aceptan pasivamente las opciones que han sido predeterminadas por otros. En teoría, la aceptación de una opción predeterminada podría considerarse una decisión consciente y válida. Pero en la práctica, la aceptación de una opción predeterminada refleja otras fuerzas [psicológicas]". BesheARs, J. et al., "How are preferences revealed?", Journal of Public Economics, vol. 92 n. ${ }^{\circ}$ 8-9, 2008, 1788.

26 "Las lecciones de la economía del comportamiento muestran que las opciones predeterminadas son pegajosas como consecuencia de varios sesgos cognitivos. [...] Numerosos experimentos han de- 
Por elementales cuestiones de espacio, no es posible en este artículo referirse a la abultada literatura sobre los factores de orden psicológico que explican el porqué de la "pegajosidad" de las opciones predeterminadas ${ }^{27}$. En lo que sí se hará énfasis es en que, pese a que la doctrina jurídica (especialmente la de tradición civilista) suela afirmar que las reglas predeterminadas están ahí precisamente para ser modificadas autónomamente según le convenga a cada persona, al mismo tiempo, la cuestión de la "pegajosidad" de la regla no es algo de lo que se haya ocupado explícitamente la misma doctrina, o bien, si lo ha hecho, ha sido de forma algo tangencial o intuitiva. A manera de ilustración sobre este punto, vale mencionar que dicha "pegajosidad" de las opciones predeterminadas fue la consideración central -aunque implícita-que tuvo la Comisión Europea para ordenar a Microsoft modificar el programa de instalación de Windows. Así, en este caso podría conjeturarse que el juez supuso -con razón- que la tendencia sistemática de los usuarios a no actuar, y por tanto a dejar el Explorer como la elección definitiva de navegador, no obedecía a que los usuarios necesariamente consideraran el Explorer como la "mejor" opción, sino a que, por ser la opción predeterminada, entonces ella tendía a quedarse "pegada" a la decisión individual (de no actuar) ${ }^{28}$. En este orden de ideas, y para contrarrestar el efecto adverso de la "pegajosidad" de la opción predeterminada, la Comisión ordenó a Microsoft que modificara la "arquitectura" de la instalación de Windows de manera

mostrado que las personas prefieren desproporcionadamente el statu quo o la opción predeterminada sobre tener que elegir activamente un cambio en su decisión o circunstancias". LUOTO, J. y CARMAN, K., Behavioral Economics Guidelines with Applications for Health Interventions, Washington, Inter-American Development Bank, 2014, 12. En el mismo sentido, véase también Choi, J. et al., "Passive decisions and potent defaults", en Wise D., Analyses in the Economics of Aging, Chicago, University of Chicago Press, 2005, 59-78.

27 Según Sunstein, existen tres factores principales que explican la "pegajosidad" de las reglas predeterminadas: (i) la inercia y procrastinación, es decir, la tendencia de las personas a mantener inconscientemente el status quo; por otro lado, existe lo que se denomina (ii) una señal informacional, esto es, que las personas perciben la regla predeterminada como una especie de "sugerencia del fabricante", luego se valen de la heurística de que el fabricante está mejor informado sobre lo que les conviene a ellos, por lo que, a menos que se cuente con una buena razón particular, pareciera mejor no ir en contra de la sugerencia. Finalmente se encuentra (iii) la aversión a la pérdida, lo que significa que la utilidad derivable de la modificación de la regla predeterminada tiende a percibirse como más elevada que la desutilidad que se deriva de la misma modificación. Sunstein, C., Choosing Not to Choose: Understanding the Value of Choice, New York, Oxford University Press, 2015, 34 ss.

28 Este argumento fue reiterado en otro caso judicial al que se enfrentó también Microsoft, pero respecto de su reproductor multimedia predeterminado (Windows Media Player). En este caso, se dice que "Microsoft reconoció que algunos consumidores rechazaban el reproductor multimedia predeterminado y descargaban un reproductor de la competencia. Pero muchos consumidores se quedaban pegados [stick] al reproductor predeterminado. Por tanto, el Tribunal de Primera Instancia sostuvo que aquellos consumidores 'que se encontraban con el Windows Media Player preinstalado en sus computadores, generalmente estaban menos inclinados a usar otro reproductor'”. STUCKe, M., "Behavioral antitrust and monopolization", cit., 565. 
tal que la estructura de la opción predeterminada fuese sustituida por una estructura de "elección activa" opcional ${ }^{29}$.

Empero, pese a que el precitado caso de Microsoft da algunas señales acerca de los efectos negativos derivables de la "pegajosidad" de la opción predeterminada, y de la manera como las empresas pueden aprovecharse de este efecto, en desmedro de sus consumidores, existen otros casos en los cuales dicha "pegajosidad", en lugar de ser contraproducente, genera consecuencias particularmente positivas. Al respecto como se mencionó de pasada- existe una abundante literatura que analiza los efectos individuales y agregados que produce el hecho de que, al momento de ser contratado un trabajador, la opción predeterminada sea que este queda inscrito en un plan de ahorro para pensiones (regla opt-out $)^{30}$. Sobre el particular, el seminal estudio de Madrian y Shea ${ }^{31}$ demuestra que, cuando la decisión de ingresar al programa de ahorro depende enteramente de una "elección activa" (regla opt-in), la tasa de participación en el programa es del $37 \%$ en el mediano plazo; en contraste, con una regla opt-out la tasa de participación se eleva al $86 \%$. El mismo estudio demuestra que el porcentaje predeterminado de descuento del salario dirigido al ahorro tiende también a quedarse "pegado" a la decisión. De manera que, incluso después de varios años, los trabajadores continúan actuando pasivamente y no modifican el porcentaje de retención establecido de manera predeterminada por los empleadores al momento de la contratación. De hecho, también se resalta que dicha "pegajosidad" tiende a ser incluso más pronunciada cuando se trata de trabajadores menos educados, mujeres o personas de raza negra. Por tanto, se concluye que el hecho de que la opción predeterminada sea "pegajosa" no solo puede producir efectos positivos, sino que suele hacer que los beneficios del efecto sean más marcados en el caso de personas (trabajadores) más vulnerables.

Con todo, la "pegajosidad" de una opción predeterminada es un fenómeno generalizado que ocurre con independencia del contenido sustancial de dicha opción, y que también es independiente del contexto de toma de decisión, ya sea que se trate de software, del derecho contractual, del derecho de habeas data, etc. Sin embargo, si a ello le agregamos la precitada idea de que el diseño de tales opciones es la consecuencia premeditada de un "arquitecto de la decisión" (I.C), entonces es fácil concluir que este "arquitecto" puede utilizar las opciones predeterminadas como un instrumento para, indistintamente, conducir al individuo (y a la sociedad misma) a resultados beneficiosos o perjudiciales.

Este último punto permite dar apertura a una segunda cuestión problemática (de orden normativo) relativa a las opciones predeterminadas como objeto de estudio, tal como se explica en el siguiente literal.

29 Lunn, P., Regulatory Policy and Behavioural Economics, oECD Publications, 2014, 33.

30 Véase supra, nota 24.

31 Madrian, B. y SHEA, D., "The power of suggestion: inertia in 401(k) participation and savings behavior", cit. 


\section{B. La cuestión normativa asociada a las reglas predeterminadas de decisión}

Teniendo en mente la idea de la "pegajosidad" de las opciones predeterminadas y que el diseño de estas es el resultado de un proceso previo y deliberado de un "arquitecto de la decisión" (v.gr., ingeniero de software, empleador o regulador), puede afirmarse entonces que la cuestión - desde una perspectiva normativa- de "cómo" debiera estar diseñada dicha opción, o si es que ella acaso debería existir, se torna en una cuestión particularmente relevante y problemática, esto incluso desde una perspectiva ética, especialmente en el contexto de la autonomía y la libertad de decisión individual $^{32}$.

Así las cosas, en esta parte del artículo se delinean algunos puntos centrales de reflexión en torno a dos cuestiones de orden normativo en específico: por un lado, (i) ¿en qué casos debería o no existir una opción predeterminada de decisión?, y, por tanto, ¿por qué ciertas cuestiones (incluso en el contexto del derecho) parecen poder resolverse sin objeción a través de reglas predeterminadas mientras que otras veces esta misma estructura resulta (éticamente) objetable?; y por otro lado, (ii) dadas las eventuales objeciones que suscita el uso de opciones predeterminadas en ciertas áreas del derecho, ¿qué criterios normativos podrían sugerirse respecto de la manera cómo debieran diseñarse estas?

\section{1. (De nuevo) opción predeterminada vs. elección activa}

En su orden, para abordar la primera cuestión señalada, es necesario tener presente la idea de que la estructura de toma decisión de la opción predeterminada se opone a la estructura de "elección activa" (I.A) y, al mismo tiempo, se opone a la estructura de las "reglas imperativas" (I.B). Dejando de lado esta última ${ }^{33}$, ya se indicó que la estructura de la "elección activa" es aquella en la que no existe ninguna opción predeterminada. De suerte que podría sostenerse que para convertir una estructura de toma decisión de opción predeterminada en una de "elección activa" bastaría

32 Sobre el particular, por ejemplo, Smith et al. advierten que, dada la "pegajosidad" de las opciones predeterminadas, entonces estas reglas pueden actuar como una especie de "manipuladores ocultos" que, desde una perspectiva ética, pueden incidir negativamente en la autonomía individual. Sмітн, N. C., Goldstein, D. y Johnson, E., "Choice without awareness: ethical and policy implications of defaults", Journal of Public Policy \& Marketing, vol. 32 n. ${ }^{\circ} 2,2013,159-172$. En el mismo sentido, Bovens sostiene que existe un trasfondo ético pues las opciones predeterminadas "funcionan mejor en la oscuridad", es decir, a espaldas de las personas. En opinión del autor, entre más se les informa a las personas que su decisión está siendo interferida por una opción predeterminada, menos efectiva es esta. Bovens, L., "The ethics of nudge", en Grüne-Yanoff, T. y Hansson, S., Preference Change, Dordrecht, Springer, 2009, 207-219.

33 Para una discusión de orden normativo acerca de cuándo resulta preferible establecer "reglas imperativas" sobre "reglas predeterminadas" y viceversa, en el contexto del derecho de contratos, véanse ARruÑADA, B., "The role of institutions in the contractual process", cit. 152 y ss., y Ayres, I., "Regulating opt-out: an economic theory of altering rules", Yale Law Journal, vol. 121, 2012, 2032-2116. 
simplemente con eliminar dicha regla. Sin embargo, esto, más que una solución, es el comienzo de otros problemas inadvertidos por la doctrina.

En efecto, nótese que la medida adoptada por la Comisión Europea en el caso de Microsoft fue que la opción predeterminada de navegador (Explorer) debía eliminarse del sistema operativo y sustituirse por una estructura de "elección activa" por parte del usuario. En concordancia con las consideraciones de la Comisión, podría conjeturarse que en este caso Microsoft, más que pretender favorecer los intereses de los usuarios a partir de la inclusión del Explorer en la instalación de Windows (lo que, al menos, ahorraría la molestia a los usuarios de tener que descargar otro navegador), en realidad buscaba favorecer sus propios intereses empresariales, aprovechándose de la posición dominante de Microsoft en el mercado de sistemas operativos y valiéndose de la "pegajosidad" de las opciones predeterminadas.

Lo indicado sugiere una hipótesis (de orden normativo) que se expresa en que, cuando quien diseña la regla predeterminada de decisión -el "arquitecto de la decisión"- tenga intereses para predeterminar una opción lo favorezca, y eventualmente ello pueda afectar negativamente a aquellos que deben decidir o a terceros, esto es un argumento para prescindir de la opción predeterminada de decisión y, en su lugar, supeditar enteramente la decisión individual a una "elección activa".

Empero, aunque esta hipótesis pareciera prima facie consistente, lo cierto es que su justificación e instrumentalización en la realidad puede resultar bastante problemática. En efecto, aunque en el precitado caso de Microsoft se infiere que esta empresa había diseñado premeditadamente el Windows y la opción predeterminada de navegador con el fin de beneficiarse a sí misma, y eventualmente afectar negativamente a los navegadores competidores y a los usuarios del sistema operativo de estos, existen otros casos análogos en los que esta misma circunstancia es bastante más sutil. Sobre este particular, basta con considerar de nuevo el precitado caso de la regulación colombiana sobre privacidad y tratamiento de datos personales por parte de las empresas.

$\mathrm{Al}$ respecto, teniendo en mente la "pegajosidad" de la opción predeterminada, ¿acaso la regla predeterminada tipo opt-out (adoptada en el art. 10.4 del Decreto 1377 de 2013) no supone un mayor beneficio para las empresas que una regla tipo opt-in, en la medida en que, con la primera, las mismas empresas contarían con una mayor cantidad de personas que con su inacción aceptarían que sus datos personales fuesen almacenados y utilizados por ellas? De otro lado, ¿acaso el simple hecho de que las empresas almacenen información personal no puede representar, cuando menos, una potencial afectación negativa a los intereses de las personas o usuarios? Si la respuesta a esta o aquella pregunta es afirmativa, ¿sugiere esto entonces -según la tesis normativa defendida líneas atrás- que debiera modificarse la regulación local de forma tal que la decisión individual sobre tratamiento de datos no se sujete a una regla predeterminada tipo opt-out, sino que lo haga enteramente a la "elección activa" de las personas titulares de la información?

Es difícil dar una respuesta en uno u otro sentido a las preguntas recién formuladas, sin embargo, estas preguntas sugieren una consideración adicional respecto de 
en qué circunstancias resulta objetable la utilización de una opción predeterminada de decisión, y por tanto es de preferir una estructura de "elección activa". En concreto, aunque se pueda argumentar que es plausible suponer que la regla tipo opt-out sobre privacidad y tratamiento de datos personales adoptada en Colombia resulta beneficiosa para las empresas, es cuando menos incierto que la misma regla perjudique a todas las personas titulares de la información; en efecto, puede darse el caso de que las beneficie. Así, el hecho de que una empresa trate información de personas les puede significar a estas un beneficio en la medida en que eventualmente podrían contar, por ejemplo, con la posibilidad de recibir publicidad "a la medida" de sus preferencias. De suerte que, en este caso, existen argumentos para sostener que la regla predeterminada adoptada en Colombia produce, cuando menos, resultados heterogéneos (positivos y negativos) respecto de diferentes consumidores.

En este orden de ideas, cuando en cierta circunstancia exista un alto grado de heterogeneidad en las preferencias individuales, o cuando exista un alto grado de incertidumbre por parte del "arquitecto de la decisión" (v.gr., el regulador) respecto de la determinación del contenido de dichas preferencias, ello constituye una razón adicional para preferir -desde un punto de vista normativo- el establecimiento de una estructura de toma de decisión de "elección activa" 34 . Contrario sensu, cuando las preferencias de las personas son más o menos homogéneas y son relativamente fáciles de identificar - por parte del regulador-, sería entonces preferible optar o permitir la utilización de una estructura que establezca una opción predeterminada, cuyo contenido refleje las preferencias de esa misma mayoría de personas ${ }^{35}$.

Así por ejemplo, no existen razones objetivas que soportaran la idea de que el Explorer fuese -en su momento (ni hoy tampoco) - un mejor navegador que sus competidores. De hecho, no debería pasarse por alto que para comienzos de 2009 (previo a la citada decisión de la Comisión Europea) el Explorer tenía la misma

34 En cuanto a la heterogeneidad de las preferencias individuales como justificación de la "elección activa", Carroll et al. afirman que "[1] as reglas predeterminadas son socialmente deseables cuando la mayoría de los agentes comparten una decisión que se considera óptima y la regla predeterminada conduce a este óptimo [...]. Pero incluso una regla predeterminada bien elegida puede ser indeseable si las decisiones óptimas de los agentes son altamente heterogéneas entre sî”. CARroll, G., CHOI, J., Laibson, D., Madrian, B. y Metrick, A., "Optimal defaults and active decisions", cit., 1640. A su turno, y respecto de la importancia del grado de certidumbre en la identificación del contenido de las preferencias individuales por parte del regulador, Sunstein sostiene que "[s]i los funcionarios del gobierno están sesgados o están inadecuadamente informados, y si la regla predeterminada no es más que una suposición, entonces esa regla puede conducir a las personas en una dirección equivocada". SunsteIn, C., "Deciding by default", University of Pennsylvania Law Review, vol. 162, n. 1, 2013, 43.

35 Esta idea encuentra apoyo explícito en el análisis económico (convencional) del derecho de contratos. Así, desde la perspectiva iuseconómica se ha sostenido que, a fin de reducir los efectos negativos derivados de los costos de transacción, las reglas predeterminadas en el derecho de contratos (reglas supletivas) deben tender a replicar los términos en los que hipotéticamente la mayoría de las partes estarían de acuerdo. La misma literatura iuseconómica suele denominar este tipo de reglas como "reglas predeterminadas mayoritarias" (majoritarian defaults). Sobre este punto, véase BARNETT, R., "The sound of silence: default rules and contractual consent", cit., 894; y Monroy, D., "Reglas supletivas 'sancionatorias' en el derecho de contratos colombiano”, cit., 223. 
participación de mercado que el navegador Firefox (cada uno con el 45\%). Hoy, más de diez años después de la decisión judicial en comento, el Explorer (ahora Edge) tiene una participación en el mercado de entre el 3\% y el 4\%, mientras que la del navegador Chrome es de más del $80 \%^{36}$. Así las cosas, en lo que se refiere a la elección de un navegador de Internet, es preciso tener en cuenta que existe un alto grado de dinamismo y de heterogeneidad en las preferencias de los usuarios, lo que -de conformidad con lo señalado en el párrafo anterior- se consideraría un argumento que sigue hoy vigente para insistir en que la decisión de los usuarios (de software) se delegue enteramente a una "elección activa" y no a opciones predeterminadas ${ }^{37}$.

Ahora, en el caso de la regulación colombiana sobre la privacidad y el tratamiento de datos personales, afirmar que la regla predeterminada efectivamente adoptada por el regulador puede desfavorecer las preferencias de algunas personas y simultáneamente favorecer las de otras equivale a afirmar que en este caso también existe un alto grado de heterogeneidad en las preferencias individuales, luego existe también un alto nivel de incertidumbre para identificar el contenido de estas preferencias por parte del regulador. Si esto es así, resulta objetable (desde una perspectiva normativa) que, en la regulación local, la decisión de los titulares de la información sobre el almacenamiento y tratamiento de datos haya quedado estructurada en torno a una regla predeterminada tipo opt-out, cuando por el contrario, según lo señalado, esta decisión hubiera debido quedar delegada enteramente a la "elección activa" de las personas titulares de la información, o lo que es lo mismo, a un sistema opt-in.

\section{Acerca de la mera existencia y del contenido de la regla predeterminada}

Recién se ha señalado que si las preferencias de las personas son más o menos homogéneas entre sí y son relativamente fáciles de identificar por parte del regulador, entonces el contenido de la opción predeterminada debería tender a reflejar dicha homogeneidad. Al respecto, en el análisis económico del derecho de contratos este tipo de reglas se denominan "reglas predeterminadas mayoritarias" (majoritarian defaults $)^{38}$. Nótese que esta idea pretende sugerir una respuesta a la pregunta de

36 Véase W3schools, "The Most Popular Browsers 2002-2020", [en línea], disponible en: https:// www.w3schools.com/browsers/ [consultado el 15 de septiembre de 2020].

37 La preocupación de las autoridades de competencia de hace diez años sobre cómo Microsoft se valía de la "pegajosidad" de la opción predeterminada para mantener y ganar participación en el mercado de navegadores parece estar replicándose hoy día con Google y su sistema Android. Para julio de 2020, Google poseía una dominancia de entre el $74 \%$ y el $80 \%$ del mercado de sistemas operativos de smartphones y al tiempo (en la mayoría de las jurisdicciones) su Android incluía como opción predeterminada el navegador Chrome. Para una discusión jurídica preliminar en torno a la preocupación actual de que Google incluya el navegador Chrome como opción predeterminada, véase Edelman, B. y Geradin, D., "Android and competition law: exploring and assessing Google's practices in mobile", European Competition Journal, vol. 12, n. ${ }^{\circ} 2-3,2016,159-194$, y GINSBERG, A., "Google - Do not pass go, do not collect \$200: why the tech giant is a 'bad' monopoly", Hastings Law Journal, vol. 71, n. ${ }^{\circ} 3,2020,783-812$.

Véase supra, nota 35. 
orden normativo de cómo debieran diseñarse estas reglas -cuando menos- en el derecho de contratos. Sin embargo, al pretender extender esta misma respuesta a otros ámbitos relevantes del derecho, se desatan no pocos (nuevos) problemas.

Por ejemplo, supóngase que en una sociedad -como la colombiana- se sabe que el $60 \%$ de las personas profesan la religión católica. Pese a este alto grado de homogeneidad de las preferencias individuales, resulta anticipadamente ilegítimo que el ordenamiento estableciera una regla predeterminada que indicara que en caso de inacción de la persona se asume que ha aceptado adherirse a dicha religión. En el mismo sentido, aun si, por ejemplo, la mayoría de un grupo de personas fueran afines al partido político de gobierno, resultaría anticipadamente inadmisible que se estableciera una regla predeterminada que indicara que la inacción de una persona (v.gr., aquella que decidió no votar en una elección) fuera asumida como voluntad individual de adherirse a las ideas y propuestas de dicho partido político.

Este par de ejemplos sugieren que el simple hecho de que exista incluso una alta homogeneidad entre las preferencias e intereses de las personas de un grupo es una justificación insuficiente para establecer una "regla predeterminada mayoritaria"; y al mismo tiempo que, aun asumiendo que las reglas predeterminadas no fuesen "pegajosas" (II.A), es decir, incluso si aceptamos que estas reglas efectivamente garantizan el continuиm de la libertad de elección individual (ı.B), existen ciertas reglas predeterminadas que se consideran prima facie objetables. Lo que no está claro es por qué, pese a existir un alto grado de homogeneidad en las preferencias individuales en una sociedad, la mera existencia de ciertas reglas predeterminadas o de ciertos contenidos de estas se considera inadmisible. En lo que resta de esta subsección intentamos formular una respuesta a esta pregunta.

Para comenzar, la pregunta en cuestión posee múltiples aristas, y todas estas pueden conducir a nuevos problemas. Así, una primera respuesta -relativamente predecible- es que en cuestiones individuales particularmente importantes y sensibles para cada persona, tales como la filiación política o la tendencia religiosa, resulta inadmisible que el ordenamiento siquiera "sugiera" alguna decisión individual. Si se afirma que en ocasiones las personas no toman "elecciones activas" pues asumen las reglas predeterminadas como "sugerencias" de otras personas que se supone que están mejor informadas ${ }^{39}$, entonces es fácil concluir por qué en estos casos el ordenamiento debería prescindir del uso de opciones predeterminadas. Sin embargo, el problema que surge de esta primera respuesta es que esta desplaza la discusión a determinar objetivamente qué cuestiones se consideran particularmente importantes y sensibles, para entonces en esos casos objetar alguna "sugerencia" mediante reglas predeterminadas. Por ejemplo, ¿cuál es la razón para que se objete el uso de estas reglas en cuestiones como la tendencia religiosa pero no en temas como el habeas

39 Respecto de las opciones predeterminadas entendidas como "sugerencias del fabricante", véase Sunstein, C., Choosing Not to Choose: Understanding the Value of Choice, cit. 
data o la donación de órganos post mortem?, ¿cuál es el criterio para determinar que en aquel caso es reprochable y en estos no?

Así las cosas, y en procura de dar una mejor respuesta a las preguntas en cuestión, se procede a sugerir dos criterios puntuales y estrechamente vinculados entre sí. El primer criterio tiene que ver con la mayor o menor amplitud que se le conceda a la noción de autonomía y "libertad" de elección individual, mientras que el segundo se refiere al tipo de objetivos que debería pretender satisfacer una regla predeterminada.

En lo relativo al primer criterio, y aunque existen diferentes posiciones filosóficas respecto del mayor o menor valor de la libertad de elección, nosotros nos concentraremos aquí en dos de ellas, una "minimalista" y otra "maximalista". Estas posiciones coinciden en la tesis de que la libertad en particular y la autonomía individual en general, por sí mismas, constituyen el valor más importante a satisfacer. Sin embargo, una y otra difieren en las condiciones que deben cumplirse para que este valor se satisfaga.

Por un lado, el libertarismo "minimalista" considera que para satisfacer el valor en comento basta con "no bloquear" la decisión individual. Por tanto, la versión "minimalista" puede pasar por alto el problema de la "pegajosidad" de la regla predeterminada, en el sentido de que, aunque se acepte dicha influencia en la decisión individual, no por ello tal decisión está o queda bloqueada. Así las cosas, la tesis "minimalista" es prima facie favorable a utilizar opciones predeterminadas en cualquier ámbito del derecho, y si acaso llegará a objetar estas reglas si es que su contenido conduce o sugiere al individuo un resultado eventualmente perjudicial para sí mismo (como sucedía en el precitado caso de Microsoft y el Explorer) o indeseable en términos colectivos (como ocurre con el sistema opt-in en materia de donación de órganos). Por tanto -en términos normativos-, podría afirmarse que el libertarismo "minimalista" tiende a defender un amplio campo de acción para las reglas predeterminadas, siempre que a juicio del regulador (arquitecto de la decisión) el contenido de la regla procure el bienestar del destinatario de la regla o de la sociedad en su conjunto. Valga decirlo, esta visión minimalista de la libertad de elección es consecuente y encaja en la conocida noción de "paternalismo libertario" defendida por los célebres Richard Thaler y Cass Sunstein ${ }^{40}$.

Por otro lado, la postura "maximalista" de la libertad (que es de hecho una objeción explícita al mencionado "paternalismo libertario" de Thaler y Sunstein) defiende que, independientemente del buen criterio del "arquitecto de la decisión" y del nivel de bienestar individual que pueda producir una norma, se considera que

40 Estos autores aceptan que las reglas predeterminadas influencian fuertemente las elecciones individuales, de ahí que estas deben dirigirse a maximizar el bienestar de las personas. El "paternalismo libertario" en general y las reglas predeterminadas en específico son consistente con el libertarismo minimalista en la medida en que las personas son libres de optar por una decisión diferente si es lo que quieren, luego, lo importante es que la regla "no bloquee" las decisiones individuales. Véase Sunstein, C. y Thaler, R., "Libertarian paternalism is not an oxymoron”, cit., 1161. 
la autonomía y la libertad en la toma de decisión poseen por sí mismas un valor independiente y superior" ${ }^{41}$. En este sentido, el libertarismo "maximalista" sostiene que incidir de cualquier manera en la decisión individual, incluso si el regulador está seguro de que este individuo se está dirigiendo a un resultado desfavorable para sí mismo (v.gr., no ahorrar lo suficiente para la pensión), no es más que una reprochable forma de instrumentalización e infantilización de las personas ${ }^{42}$. Por tanto, según esta postura maximalista, incluso el derecho individual a equivocarse se ubica por encima de la pretensión de que otros (v.gr., el regulador) pretendan que las personas busquen su propio bienestar ${ }^{43}$. Con todo, si se asume que las reglas predeterminadas inciden por sí mismas en la toma de decisión, entonces un "maximalista de la libertad" las considerará siempre objetables ${ }^{44}$.

Ahora bien, del contraste entre las visiones minimalista y maximalista de la libertad se extraen dos consideraciones relevantes. (i) Mientras el libertarismo minimalista sugerirá un amplio campo de acción para las reglas predeterminadas y en múltiples contextos del derecho, el libertarismo maximalista tenderá a objetarlas en cualquier contexto, luego este último defenderá que las normas y la toma de decisión se estructuren a través de "elecciones activas" 45 . Por otro lado, (ii) si la perspectiva "minimalista" defiende que la regla predeterminada debe diseñarse a fin de -cuando menos- prevenir resultados perjudiciales para el propio individuo, con lo que configura una visión eminentemente "paternalista", en contraste, la versión "maximalista" sugiere que incluso el derecho a equivocarse antecede a pretender -a través de una regla- que el individuo maximice su propio interés individual, configurando con ello una versión eminentemente "anti-paternalista"46.

41 Rebonato, R., "A critical assessment of libertarian paternalism”, Journal of Consumer Policy, vol. 37 n. $3,2014,381$ ss.

42 White, M., "Behavioral law and economics: the assault on consent, will, and dignity", en FAvor C. et al., Essays on Philosophy, Politics \& Economics: Integration \& Common Research Projects, Stanford, Stanford University Press, 2010, 215 ss.

43 Sunstein identifica esta versión "maximalista de la libertad" con la idea de que "[1]a libertad de elección tiene un valor intrínseco no solo porque muchos valoramos de forma independiente el derecho a elegir [...] sino también, y de modo fundamental, porque los seres humanos tienen dignidad y el derecho a hacer cuanto deseen". SunteIn, C., Paternalismo libertario, Barcelona, Herder, 2017, 151. Para una descripción más detallada de esta postura "maximalista de la libertad", véase también WRight, J. y GinsBuRG, D., "Behavioral law and economics: its origins, fatal flaws, and implications for liberty", Northwestern University Law Review, vol. 106, n. ${ }^{\circ} 3,2012,1070$ ss.

44 Wilkinson, T. M., "Nudging and manipulation", Political Studies, vol. 61, n. ${ }^{\circ}$ 2, 2013, 341-355.

$45 \mathrm{Al}$ respecto, véase, por ejemplo, la discusión de MacKay y Robinson, quienes, amparados en un argumento libertario "maximalista", objetan la utilización de cualquier tipo de regla predeterminada en el contexto de la donación de órganos, luego defienden acá la utilización de una estructura de "elección activa forzosa". MACKAY, D. y RoBINSON, A., "The ethics of organ donor registration policies: nudges and respect for autonomy", The American Journal of Bioethics, vol. 16, n. ${ }^{\circ} 11,2016$, 3-12.

46 Esta idea de "anti-paternalismo" resulta consistente con la idea de "soberanía del consumidor" defendida por Mises, según la cual ser soberano en este caso no significa que el consumidor esté libre de defectos, pues lo cierto es que muchas veces los consumidores compran y consumen cosas que los 
Con estas consideraciones en mente, contamos con elementos suficientes para hacer una aproximación alternativa a la cuestión planteada acerca de por qué la mera existencia de ciertas reglas predeterminadas o ciertos contenidos de estas (v.gr., aquellas que predeterminen la filiación política o la tendencia religiosa) se consideren inadmisibles. La hipótesis sobre este punto es que, con independencia de que se asuma una posición libertaria minimalista o una maximalista, las dos perspectivas refutarían el uso de este tipo de reglas predeterminadas en estos casos.

Por un lado, desde la postura "maximalista", si la "elección activa" es siempre preferible a la decisión estructurada en torno a una regla predeterminada, entonces cuestiones como la filiación política o religiosa, la voluntad de donar órganos, el tratamiento de datos personales por parte de las empresas, son otros tantos casos en que se aplicaría este argumento. Empero, hay un argumento maximalista adicional más contundente para favorecer la "elección activa" sobre la regla predeterminada en este tipo de decisiones.

En efecto, dado que la postura "maximalista" - luego anti-paternalista- otorga una posición privilegiada al derecho a equivocarse, entonces esta perspectiva supone a su vez un mayor sentido de compromiso moral individual respecto de las consecuencias -incluso perjudiciales- de la decisión, en comparación con la opción de delegar esta misma decisión en otro. Según esta tesis, en presencia de una regla predeterminada, si las personas optan por no actuar, están delegando la decisión y sus consecuencias a lo predeterminado en la regla misma, y por tanto el sentido de compromiso y responsabilidad moral respecto de la decisión tiende a atenuarse ${ }^{47}$. Así las cosas, es plausible sostener que cuando una persona elige activamente que una empresa guarde y utilice su información personal, ello genera un mayor sentido de compromiso individual si es que esta decisión le resultare perjudicial en el mediano o largo plazo, en comparación con la alternativa de que este mismo resultado sea la consecuencia de la inacción respecto de una regla predeterminada. En igual sentido, cuando se hace una elección política activa (v.gr., emitir un voto por un candidato o por un partido político en específico), esto genera una mayor responsabilidad moral de ese votante respecto de lo que haga el candidato elegido, luego, a priori, esto tendería a reforzar su compromiso para tomar una mejor elección política ${ }^{48}$.

perjudican. De manera que ser soberano incluye el derecho a cometer errores, es decir, "el derecho a ser tonto", y nadie, ni el Estado, debe obstaculizar el ejercicio de este derecho. Mises, L. v., Economic Policy Thoughts for Today and Tomorrow, Alabama, Ludwig von Mises Institute, 2006, 21.

47 Sobre este mismo punto, Bartling y Fischbacher sostienen que cuando en la decisión individual interviene o se delega en otro, ello tiende a reducir el sentimiento de culpa y responsabilidad individual si es que las consecuencias de la decisión son negativas. Contrario sensu, cuando la persona toma una decisión directamente, sin la intervención o delegación de otro, ello genera un mayor nivel de responsabilidad moral respecto de las consecuencias (negativas) de la decisión. Véase BARTLING, B. y FischBACHER, U., "Shifting the blame: on delegation and responsibility", The Review of Economic Studies, vol. 79, n. ${ }^{\circ} 1,2012,67-87$.

48 Esta idea es tomada de Sunstein, quien objeta un eventual sistema de votación estructurado a partir de reglas predeterminadas. Según este autor, al voto se le asocia una connotación moral que no es 
Ahora bien, desde la postura libertaria minimalista, la razón para objetar la utilización de reglas predeterminadas en casos como la filiación política o religiosa es también predecible. Aquí el argumento se deriva de que, dado que esta postura es a su vez paternalista, entonces el establecimiento de una regla predeterminada se justifica si es que se maximiza el bienestar o se evitan resultados perjudiciales para el individuo. Por tanto, la pregunta sería la de qué beneficios eventualmente se maximizan o qué perjuicios individuales se evitan si la decisión relacionada con cuestiones como las señaladas se delegan a una regla predeterminada. Al respecto, no parece que exista alguna razón de orden paternalista que justifique que este tipo de decisiones se deleguen en una regla predeterminada de decisión.

Con todo, trátese de una postura "maximalista" o de otra "minimalista" de la libertad, lo cierto es que -en términos normativos- existe un doble argumento para que cuestiones como la filiación política o religiosa de una persona no puedan delegarse a una opción predeterminada de decisión. Por tanto, independientemente de la postura que se asuma respecto del valor de la libertad, este tipo de decisiones solo podrían restringirse a una "elección activa" y autónoma de cada individuo. Empero, como se advirtió de manera anticipada, lo cierto es que la aproximación aquí defendida conduce a nuevos problemas importantes.

Por ejemplo, se señaló en su momento que, en el caso de que una persona ingrese a una tienda, contemple los productos y salga del establecimiento comercial, no se puede deducir de esta inacción algún tipo de intención de comprar. Dada la ausencia de una regla predeterminada de decisión en este caso, a esta inacción no es posible asociarle ningún contenido ni efecto relevante. Se requiere necesariamente de una "elección activa" para determinar que el contenido de la decisión es la intención de comprar. Sin embargo, nótese que este caso de la tienda es sustancialmente diferente al de la filiación política o religiosa, pues en estos últimos a la actitud pasiva sí se le asocia un importante contenido y efecto. Así, teniendo en mente la idea de que este tipo de decisiones debieran estructurarse en torno a una "elección activa", podría afirmarse que, en el caso de la religión, tal "elección activa” equivale a realizar actos propios de cierta creencia religiosa (v.gr., recibir la comunión en la religión católica), y en el caso de la filiación política, la "elección activa" se expresa -por excelencia- en la emisión de un voto en específico. Pero en estos mismos casos, supóngase una persona que actúa pasivamente, es decir, que no realiza ningún acto propio de ninguna religión o que no vota en una elección. A diferencia de cuando aquella otra persona no actúa en la tienda, en estos otros dos casos la inacción no es algo carente de contenido jurídicamente relevante; ¿o es que acaso cuando la perso- 
na no hace ningún acto propio de alguna religión eso no nos dice nada acerca de lo que ha decidido?

Así las cosas, existen casos, como el de la filiación política o religiosa, en los cuales, aun cuando podamos oponernos a la utilización de opciones predeterminadas de decisión, y por tanto defender la necesidad de que la decisión deba estructurarse en torno a una "elección activa", en los mismos casos la ausencia de dicha elección activa, es decir, la inacción, sí se considera una manifestación inequívoca del contenido de la decisión individual y que incluso se ubica al mismo nivel de elegir activamente.

Los problemas que se derivan de lo anterior no son menores, pues implican que aun si se defiende el argumento de que en ciertas situaciones la decisión individual debe restringirse exclusivamente a una "elección activa", y por tanto se objeta cualquier tipo de influencia externa del regulador, incluso a través de cualquier tipo de opción predeterminada de decisión, paradójicamente, en estos casos es posible que el propio regulador sí esté estableciendo una regla predeterminada de decisión. Por ejemplo, si en el caso de la donación de órganos post mortem se optase por retirar del ordenamiento cualquier regla predeterminada de decisión, sea esta una regla tipo opt-in o una regla tipo opt-out, surge la pregunta: ¿qué sucede al momento del fallecimiento de la persona en caso de que tampoco exista una "elección activa" de su parte? Desde una perspectiva jurídica, ¿sería posible o no disponer de los órganos? Si la respuesta a esta pregunta es negativa, lo que se infiere es que estamos ante una regla predeterminada tipo opt-in; y si la respuesta es afirmativa, se deriva entonces que estamos ante una regla predeterminada tipo opt-out, luego no podríamos afirmar que el regulador no ha establecido acá una regla predeterminada de decisión.

La conclusión final que se extrae de lo recién indicado es una cuestión ineludible y bastante poco explorada. En efecto, desde la introducción de este artículo se sostuvo que las opciones predeterminadas de decisión son una parte siempre presente en la estructura de los diversos ámbitos de los ordenamientos jurídicos, y también se dijo que estas reglas son aquellas que -a partir de lo que a priori establezca explícitamente el regulador- describen el contenido de la decisión que se asume tomó una persona si es que "decide no decidir". Sin embargo, lo que se infiere del párrafo anterior es que a veces, cuando el regulador opta por ser completamente neutral, absteniéndose de incorporar cualquier regla predeterminada, paradójicamente, incluso de esta inacción del regulador se puede estar estableciendo una regla predeterminada, que aunque "invisible", sin duda existe.

\section{Conclusiones}

La pretensión principal del presente artículo es la de plantear - de manera no exhaustiva- algunas bases para reflexionar en torno a algunas problemáticas teóricas relacionadas con las reglas predeterminadas. Si bien en la doctrina jurídica civilista es común discutir sobre estas reglas a partir de un contraste con las "reglas impe- 
rativas", en este artículo la discusión se centra en el contraste entre aquellas y las "elecciones activas". De entre las diversas problemáticas, el artículo resalta algunas preguntas dirigidas a cuestionar bajo qué circunstancias resulta preferible proscribir la utilización de una regla predeterminada, y por lo tanto delegar enteramente la decisión individual en una "elección activa"; simultáneamente, también se sugieren algunas ideas dirigidas a enfrentar la cuestión acerca de "cómo" debiera diseñarse el contenido de las reglas predeterminadas.

Ahora bien, es importante insistir en que la aproximación que se presenta en este artículo es bastante incompleta, y por lo mismo es susceptible de complementaciones y objeciones. Por ejemplo, entre otras cuestiones, aunque en él se alude de pasada a los efectos que han tenido las reglas que predeterminan la afiliación a planes de ahorro pensional en Estados Unidos, no se efectúa ningún tipo de aproximación respecto de si, por ejemplo, resultaría conveniente que, a nivel local, la inscripción en un fondo de pensiones voluntarias continuase siendo una decisión que dependiera exclusivamente de la "elección activa" de cada trabajador, o si -dados los bajos niveles de ahorro voluntario para pensiones en Colombia- sería recomendable que el regulador optara por la inscripción en estos fondos, ordenado que la misma fuese la opción predeterminada en los contratos laborales (sistema opt-out).

Por otro lado, aunque el artículo también alude a la regulación sobre habeas data en Colombia, solo trata un punto muy concreto de dicha regulación, cuando lo cierto es que existen bastantes más expresiones de dicho derecho que bien merecen un análisis detallado a partir -quizá- de las bases teóricas que se presentan en este artículo. Sobre este punto, por ejemplo, el legislador local ha discutido poco lo relacionado con la eventual regulación del uso de cookies en internet. Al respecto, para el caso de Europa, la Directiva 2002/58/EC estableció que la aceptación de cookies no podía ser una imposición (imperativa) para los usuarios, pero dispuso asimismo que tampoco podía hacerse mediante una regla predeterminada tipo opt-out, sino que debía depender de una "elección activa" del usuario ${ }^{49}$.

Por último, consideramos que es bastante incipiente la discusión acerca de las que simplemente nombramos como "reglas predeterminadas invisibles", esto es, aquellas opciones o reglas predeterminadas de decisión que están en el derecho y que surgen como resultado de la decisión premeditada del regulador al intentar asumir una posición neutral respecto de la decisión individual. Anticipadamente, consideramos que estas "reglas predeterminadas invisibles" existen y tienen particular relevancia en ámbitos relacionados con libertades individuales, normalmente consideradas esenciales, tales como: el derecho a voto, la libertad religiosa, el derecho de autodeterminación, la libertad de expresión, entre otras. En estos casos, parece que

49 Para una discusión introductoria respecto del uso de opciones o reglas predeterminadas de decisión en lo que respecta a las cookies, véase WiLlis, L., "Why Not privacy by default?", cit. y Cofone, I. "The way the cookie crumbles: online tracking meets behavioural economics", International Journal of Law and Information Technology, vol. 25, n. ${ }^{\circ}$ 1, 2017, 38-62. 
cuando de manera premeditada se pretende no utilizar ninguna regla explícita, y por tanto "visible", que predetermine o influya en la decisión individual sobre este tipo de libertades individuales, incluso en estos casos, de forma inevitable, el regulador, y el derecho en general, sí está adoptando una regla predeterminada de decisión.

\section{Referencias}

39530 Microsoft (Tying), Asunto comp/39.530, [en línea], Comisión Europea, 16 de diciembre de 2009, disponible en: http://ec.europa.eu/competition/elojade/isef/ case_details.cfm?proc_code=1_39530

Arruñada, B., "The role of institutions in the contractual process", en DefFains, B. y Kirat, T., Law and Economics in Civil Law Countries, Amsterdam, Elsevier Science, 2001, 154.

Ayres, I., "Regulating opt-out: an economic theory of altering rules", Yale Law Journal, vol. 121, 2012, 2032-2116.

Ayres, I. y Gertner, R., "Filling gaps in incomplete contracts: an economic theory of default rules", The Yale Law Journal, vol. 99 n. ${ }^{\circ}$ 1, 1989, 87-130.

BARNETT, R., "The sound of silence: default rules and contractual consent", Virginia Law Review, vol. 78, 1992, 821-911.

BARTLING, B. y FischBACHER, U., "Shifting the blame: on delegation and responsibility", The Review of Economic Studies, vol. 79, n. ${ }^{\circ}$ 1, 2012, 67-87.

Beshears, J., Choi, J., Laibson, D. y Madrian, B., "The importance of default options for retirement saving outcomes: evidence from the United States", en BRown, J., Liebman, J. y Wise, D., Social Security Policy in a Changing Environment, Chicago, University of Chicago Press, 2009, 167-195.

Beshears, J., Choi, J., Laibson, D. y Madrian, B., "How are preferences revealed?", Journal of Public Economics, vol. 92 n. ${ }^{\circ}$ 8-9, 2008, 1787-1794.

Bovens, L., "The ethics of nudge", en Grüne-Yanoff, T. y Hansson, S., Preference Change, Dordrecht, Springer, 2009, 207-219.

Carroll, G., Choi, J., Laibson, D., Madrian, B. y Metrick, A., “Optimal defaults and active decisions", The Quarterly Journal of Economics, vol. 124, n. ${ }^{\circ}$, 2009, 1639-1674. 
Choi, J., Laibson, D., Madrian, B. y Metrick, A., "Optimal defaults", The American Economic Review, vol. 93 n. ${ }^{\circ}$ 2, 2003, 180-185.

Choi, J., Laibson, D., Madrian, B. y Metrick, A., "Passive decisions and potent defaults", en Wise, D., Analyses in the Economics of Aging, Chicago, University of Chicago Press, 2005, 59-78.

Choi, J., Laibson, D., Madrian, B. y Metrick, A., "For better or for worse: default effects and 401(k) savings behavior", en WISE, D., Perspectives on the Economics of Aging, Chicago, University of Chicago Press, 2004, 81-125.

Choi, J., Laibson, D., Madrian, B. y Metrick, A., "Defined contribution pensions: plan rules, participant choices, and the path of least resistance", Tax Policy and the Economy, vol. 16, 2002, 67-113.

Cofone, I., "The way the cookie crumbles: online tracking meets behavioural economics", International Journal of Law and Information Technology, vol. 25, n. ${ }^{\circ}$ 1, 2017, 38-62.

Dinner, I. Johnson, E., Goldstein, D. y Liu, K., "Partitioning default effects: why people choose not to choose", Journal of Experimental Psychology, vol. 17, n. 4, 2011, 332-341.

Edelman, B. y Geradin, D., "Android and competition law: exploring and assessing Google's practices in mobile", European Competition Journal, vol. 12, n. ${ }^{\circ}$ 2-3, 2016, 159-194.

Ferejohn, J. y Friedman, B., “Toward a Political Theory of Constitutional Default Rules", Florida State University Law Review, vol. 33, n. . 3, 2006, 825-860.

Gevers, S., Janssen, A. y Friele, R. "Consent systems for post mortem organ donation in Europe”, European Journal of Health Law, vol. 11, 2004, 175-186.

GinsBerg, A., "Google - Do not pass go, do not collect \$200: why the tech giant is a 'bad' monopoly”, Hastings Law Journal, vol. 71, n. 3, 2020,783-812.

Johnson, E. y Goldstein, D., “Do defaults save lives?”, Science, vol. 302, n. . 5649, 2003, 1338-1339.

Johnson E., Bellman, S. y Lohse, G. "Defaults, framing and privacy: why opting in-opting out", Marketing Letters, vol. 13, n. ${ }^{\circ}$ 1, 2002, 5-15. 
Johnson, E. y Goldstein, D., "Decisions by default", en Shafir, E., The Behavioral Foundations of Public Policy, New Jersey, Princeton University Press, 2013, 417-427.

Johnson, E., Shu, S., Dellaert, B., Fox, C., Goldstein, D., Häubl, G. y Weber, E., "Beyond nudges: tools of a choice architecture", Marketing Letters, vol. 23, n. 2, 2012, 491 .

Kesan, J. P. y Shah, R., "Setting software defaults: perspectives from law, computer science and behavioral economics", Notre Dame Law Review, vol. 82, n. ${ }^{\circ} 2$, 2006, 583-634.

Korobkin, R. "Inertia and preference in contract negotiation: the psychological power of default rules and form terms", Vanderbilt Law Review, vol. 51, n. ${ }^{\circ} 6$, 1998, 1583-1651.

Korobrin, R., "The status quo bias and contract default rules”, Cornell Law Review, vol. 83, 1998, 608-687.

Lunn, P., Regulatory Policy and Behavioural Economics, oECD Publications, 2014.

Luoto, J. y Carman, K., Behavioral Economics Guidelines with Applications for Health Interventions, Washington, Inter-American Development Bank, 2014.

MacKay, D. y Robinson, A., “The ethics of organ donor registration policies: nudges and respect for autonomy", The American Journal of Bioethics, vol. 16, n. ${ }^{\circ} 11$, 2016, 3-12.

MAdRIAn, B. y SheA, D., "The power of suggestion: inertia in 401(k) participation and savings behavior", The Quarterly Journal of Economics, vol. 116, n. ${ }^{\circ}$, 2001, 1149-1187.

Mises, L. v., Economic Policy Thoughts for Today and Tomorrow, Alabama, Ludwig von Mises Institute, 2006.

Monroy, D., “Acerca del diseño óptimo de las reglas predeterminadas en el derecho de contratos", en AA.vv., Colección Enrique Low Murtra: Derecho Económico, Bogotá, Universidad Externado de Colombia, 2017, 15-62.

Monroy, D., “Reglas supletivas 'sancionatorias' en el derecho de contratos colombiano: el caso del contrato de transporte", Revista de Derecho Privado, Universidad Externado de Colombia, n. ${ }^{\circ}$ 30, 2016, 221-254. 
Rebonato, R., "A critical assessment of libertarian paternalism”, Journal of Consumer Policy, vol. 37, n. ${ }^{\circ}$, 2014, 357-396.

Schwartz, A., "The default rule paradigm and the limits of contract law", Southern California Interdisciplinary Law Journal, vol. 3, 1994, 389-419.

Smith, N. C., Goldstein, D. y Johnson, E., "Choice without awareness: ethical and policy implications of defaults", Journal of Public Policy \& Marketing, vol. 32 n. ${ }^{\circ} 2,2013,159-172$.

STUCKe, M., "Behavioral antitrust and monopolization", Journal of Competition Law \& Economics, vol. 8, n. ${ }^{\circ} 3,2012,545-574$.

STUCKe, M., "Behavioral exploitation and its implications on competition and consumer protection policies", en AA.vv., The Pros and Cons of Consumer Protection, Växjö, Davidsons Tryckeri, 2012, 77-122.

Sunstein, C., Choosing Not to Choose: Understanding the Value of Choice, New York, Oxford University Press, 2015.

Sunstein, C. y Thaler, R., "Libertarian paternalism is not an oxymoron", The University of Chicago Law Review, vol. 70, n. ${ }^{\circ} 4,2003,1159-1202$.

Sunstein, C., "Deciding by default", University of Pennsylvania Law Review, vol. $162, n .^{\circ} 1,2013,1-57$.

Sunstein, C., Impersonal Default Rules vs. Active Choices vs. Personalized Default Rules: A Triptych, Working Paper, 2013.

Suntein, C., Paternalismo libertario, Barcelona, Herder, 2017.

Thaler, R., Sunstein, C. y Balz, J., "Choice architecture”, en Shafir, E., The Behavioral Foundations of Public Policy, New Jersey, Princeton University Press, 2013, 428-439.

W3schools, The Most Popular Browsers 2002-2020, [en línea], disponible en: https://www.w3schools.com/browsers/ [consultado el 15 de septiembre de 2020]

White, M. "Behavioral Law and Economics: the assault on consent, will, and dignity", en Favor C. et al., Essays on Philosophy, Politics \& Economics: Integration \& Common Research Projects, Stanford, Stanford University Press, 2010. 
Wilkinson, T. M., "Nudging and manipulation", Political Studies, vol. 61, n. 2 , $2013,341-355$.

WILLIS, L., "When nudges fail: slippery defaults", The University of Chicago Law Review, vol. 80, n. ${ }^{\circ} 3,2013,1155-1229$.

WiLlis, L., "Why not privacy by default?", Loyola-LA Legal Studies, Paper No. 2013-37, 2014, 1-74.

Wright, J. y Ginsburg, D., "Behavioral Law and Economics: its origins, fatal flaws, and implications for liberty", Northwestern University Law Review, vol. 106, n. ${ }^{\circ}$ 3, 2012, 1033-1090.

Zamir, E. y Medina, B., Law, Economics, and Morality, New York, Oxford University Press, 2010. 